\title{
Total synthesis of the tetracyclic indole alkaloid ht-13-A.
}

Yilin Zhang, Ian W. McArdle, Jeremiah W. Hubbard, Novruz G. Akhmedov, and Björn C. G. Söderberg.*

C. Eugene Bennett Department of Chemistry, West Virginia University, Morgantown, West Virginia 26506-6045, USA.

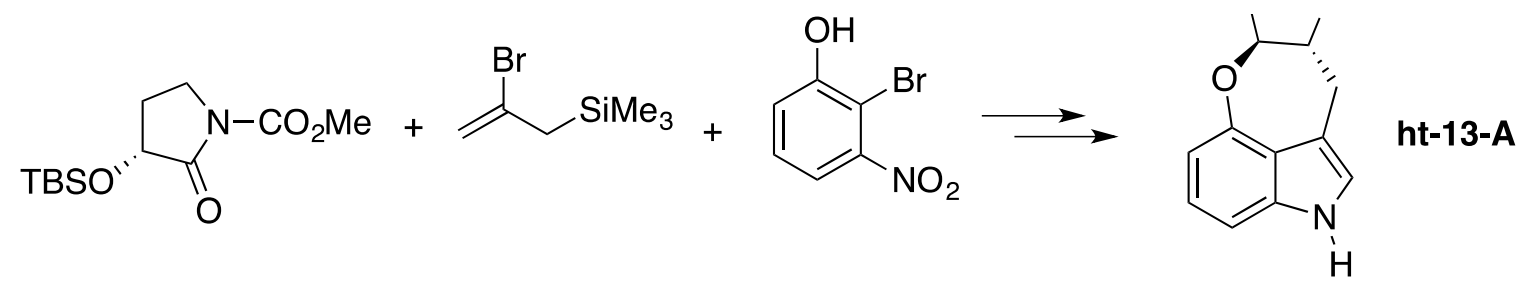

Abstract Total synthesis of the tetracyclic indole alkaloid ht-13-A is reported starting ultimately from commercially available (-)-4-amino-2-hydroxybutyric acid. The key steps in this synthesis are a Lewis acid mediated acyliminium ion allylation, a Mitsunobu reaction, a palladium catalyzed Stille-Kelly intramolecular cross coupling, and a carbon monoxide mediated palladium catalyzed reductive $N$-heterocyclization.

Introduction Two tetracyclic indole alkaloids were isolated by Kamiguchi and Yasui in 2000 from a genus of the bacteria Streptomyces sp. (PA-48561) (Figure 1). ${ }^{1}$ The structures were elucidated by ${ }^{1} \mathrm{H}$ and ${ }^{13} \mathrm{C}$ NMR, UV, IR and LRMS analyses. The alkaloids named ht-13-A and ht-13-B exhibited some affinity for serotonin receptors. To the best of our knowledge, ht-13-A and ht-13-B are the only two examples of naturally occurring 3,4-oxepino-fused indoles. In a previous study, we reported the first total synthesis of ht-13-B. ${ }^{2}$ Herein we describe a total synthesis of ht-13-A in eight steps. 

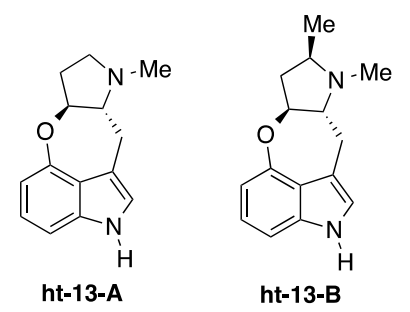

Figure 1. Indole alkaloids ht-13-A and ht-13-B.

Result and discussion $3(R)$-t-Butyldimethylsilyloxypyrrolidin-2-one $(\mathbf{1})^{3}$ was prepared in four steps from commercially available 4-amino-2(S)-hydroxybutyric acid via $3(R)$ hydroxypyrrolidin-2-one. ${ }^{4}$ The 3(R)-t-Butyldimethylsilyloxy group in $\mathbf{1}$ was anticipated to be the initial source of the two chiral centers of the target molecule. Protection of the pyrrolidinone nitrogen as a methyl carbamate $\mathbf{2}$ was achieved under standard reaction conditions (Scheme 1). Regioselective reduction of 2 using lithium triethylborohydride gave the $\mathrm{N}, \mathrm{O}$-hemiacetal $\mathbf{3}$ as an inseparable mixture of diastereomers. In our previous synthesis of $\mathrm{ht}-13-\mathrm{B}, \mathrm{,}^{2}$ a related compound was initially $O$-methylated prior to a Lewis acid mediated allylation. However, introduction of the allyl side chain via an acyliminium ion was achieved directly from 3 . In the event, reaction of 3 with 2-bromo-2-propen-1-yl trimethylsilane (4) ${ }^{5}$ in the presence of an excess of titanium tetrachloride gave compound 5 as an approximately 6:1 mixture of two inseparable diastereomers. ${ }^{6}$ The major isomer was predicted to have a cisrelationship between the allyl and the $t$-butyldimethylsilyloxy (OTBS) groups based on literature precedence. ${ }^{7}$ However, the stereochemistry of either of the isomers could not be confirmed at this point in the synthesis. The $t$-butyldimethylsilyl group was removed using tetrabutylammonium fluoride (TBAF) and at this point the 
diastereomers were readily separated by chromatography on silica gel affording pure pyrrolidines $\mathbf{6}$ and 7. The expected stereochemistry of the major isomer $\mathbf{6}$ and the minor isomer $\mathbf{7}$ was cis and trans, respectively, as confirmed by nOe NMR experiments.

Scheme 1 Synthesis of cis-3-hydroxy-2-allyl-substituted pyrrolidine 6.

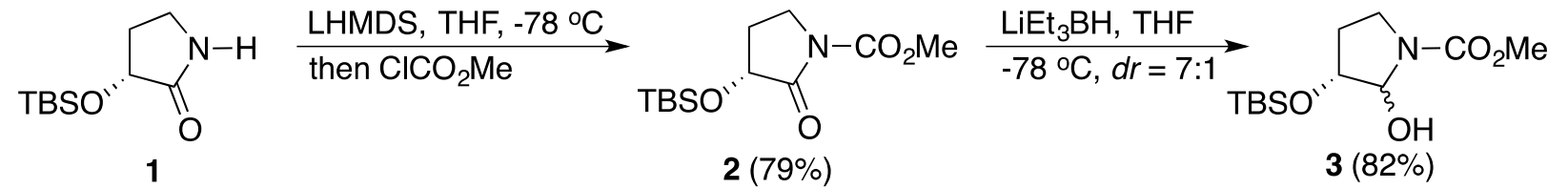

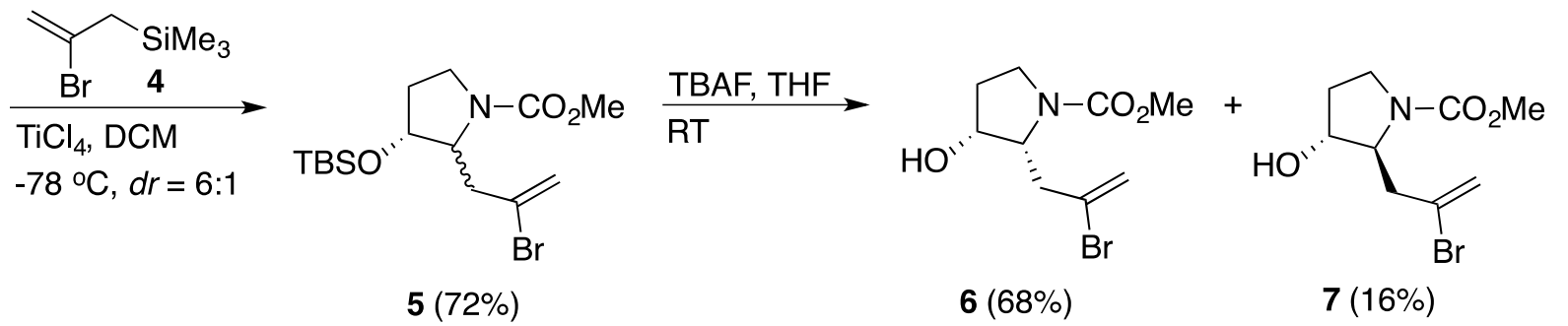

Mitsunobu reaction of the major isomer 6 with 2-bromo-3-nitrophenol (8) in the presence of triphenylphosphine and diisopropylazodicarboxylate (DIAD) furnished compound 9 (Scheme 2). The expected cis to trans inversion of stereochemistry was again confirmed by nOe NMR experiments. With the correct stereochemistry established, two sequential palladium catalyzed reactions were employed to build the oxepane and pyrrole rings of ht-13-A. The oxepane was obtained using an intramolecular Stille-Kelly ${ }^{8}$ reaction. Compound 9 was treated with hexamethylditin in the presence of a catalyst system consisting of bis(dibenzylidenacetone)palladium - triphenylphosphine producing the tricyclic compound 10. A similar yield was obtained in the synthesis of ht-13-B. In addition to the palladium based system, bis(1,5,-cyclooctadiene)nickel -2,2'-bipyridine catalyzed intermolecular cross coupling reactions between aromatic bromides have recently been reported. ${ }^{9}$ However, the same catalyst system in this transformation only 
resulted in decomposition of the starting material (9) to an intractable mixture. Palladium catalyzed reductive $N$-heterocyclization of $\mathbf{1 0}$ in the presence of carbon monoxide gave the expected tetracyclic indole $\mathbf{1 1} .^{10,11}$ Finally, the methoxycarbonyl group was reduced to a methyl group using sodium bis(2-methoxyethoxy)aluminum hydride (Red-Al) in toluene affording ht-13-A in high isolated yield. The ${ }^{1} \mathrm{H}$ and ${ }^{13} \mathrm{C}$ NMR, IR, HRMS, melting point and optical rotation data of synthetic ht-13-A were identical to the literature values of the compound isolatated by Kamiguchi and Yasui. ${ }^{1}$

Scheme 2 Completion of the synthesis of ht-13-A.
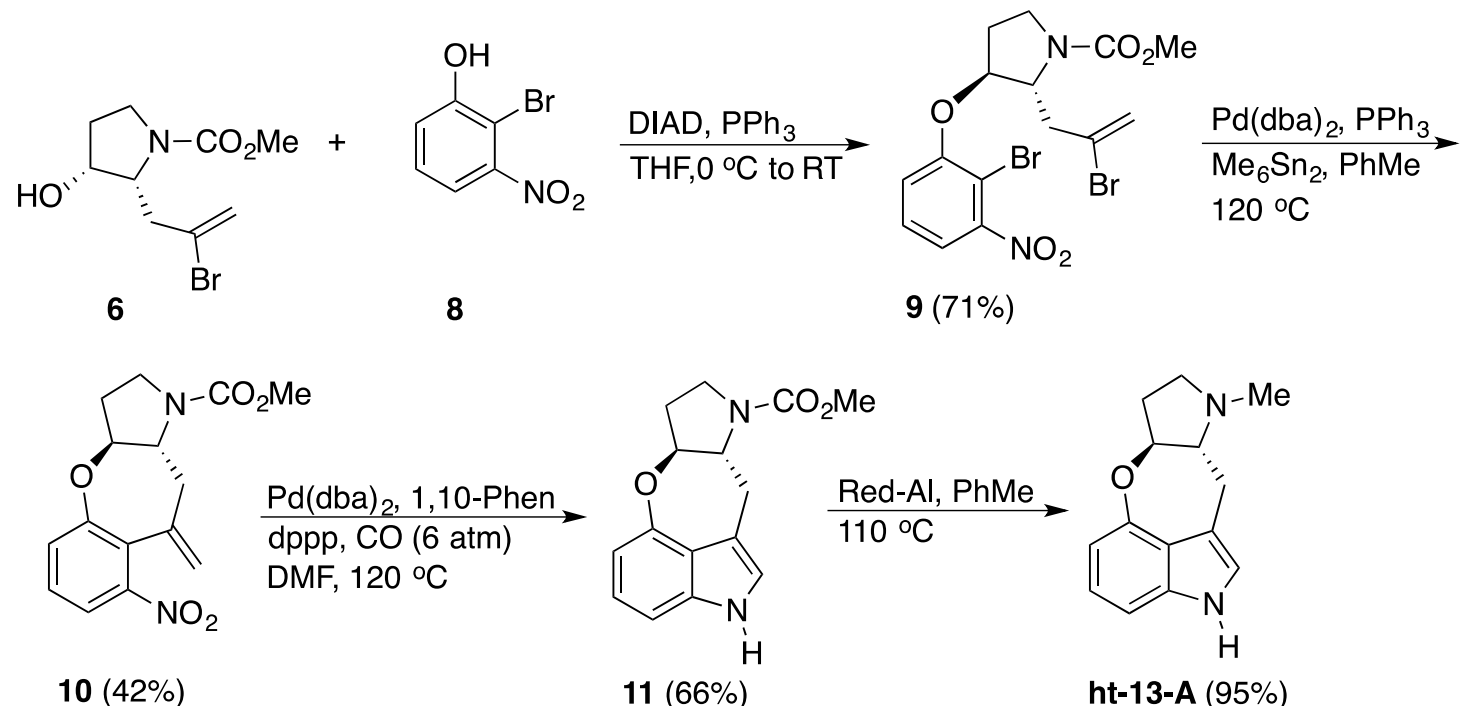

Conclusion In summary, a total synthesis of the tetracyclic indole alkaloid ht-13-A was achieved starting from commercially available (-)-4-amino-2-hydroxybutyric acid. The overall yield of ht-13-A in eight steps from pyrrolidinone 1 was $6 \%$. The trans stereochemistry was obtained from an acyliminium ion allylation followed by a Mitsunobu reaction. The 7-membered oxepane ring was obtained via an intramolecular Stille-Kelly reaction and the pyrrole ring was synthesized in a late stage carbon monoxide mediated palladium catalyzed reductive $N$-heterocyclization. 
This synthesis exemplifies a strategy for the synthesis of 3,4-fused indole alkaloids via nitro styrene precursors.

\section{Associated content}

\section{Supporting Information}

Supplementary data associated with this article including experimental procedures and ${ }^{1} \mathrm{H}$ NMR and ${ }^{13} \mathrm{C}$ NMR spectra can be found in the online version, at http://dx.doi

\section{AUTHOR INFORMATION \\ Corresponding Author}

*E-mail: bjorn.soderberg@mail.wvu.edu

\section{ACKNOWLEDGMENT}

We gratefully acknowledge the National Science Foundation (CHE-0611096) and the C. Eugene Bennett Department of Chemistry for generous support. The National Science Foundation-MRI program is also gratefully acknowledged for the funding of an NMR system (CHE-1228366) and an X-ray diffractometer (CHE-1336071). The authors would like to thank Dr. Gregory Donohoe for HRMS analyses. 


\section{REFERENCES}

${ }^{1}$ Kamigauchi, T.; Yasui, M. PCT Int. Appl. (2000), WO 2000059909, [CAN 133:267009].

2 Zhang, Y.; Hubbard, J. W.; Akhmedov, N. G.; Petersen, J. L.; Söderberg, B. C. G. J. Org. Chem. 2015, 80, 4783-4790.

${ }^{3}$ Zheng, X.; Feng, C.; Ye, J.; Huang, P. Org. Lett. 2005, 7, 553-556.

${ }^{4}$ Bjornson, K.; Canales, E.; Cottell, J. J.; Karki, K. K.; Katana, A. A.; Kato, D.; Kobayashi, T.;

Link, J. O.; Martinez, R.; Phillips, B. W.; Pyun, H.-J.; Sangi, M.; Schrier, A. J.; Siegel, D.; Taylor, J.

G.; Tran, C. V.; Trejo M., Teresa A.; Vivian, R. W.; Yang, Z.-Y.; Zablocki, J.; Zipfel, S. PCT Int. Appl. (2014), WO 2014008285, [CAN 160:190332].

5 Trost, B. M.; Grese, T. A.; Chan, D. M. T. J. Am. Chem. Soc. 1991, 113, 7350-7362.

${ }^{6}$ For a related cis-selective (cis/trans=2.7:1) allylation using 4, see: Lennartz, M.; Sadakane, M.; Steckhan, E. Tetrahedron 1999, 55, 14407-14420.

${ }^{7}$ For cis-selective allylations of closely related compounds using allytrimethyl silane and a Lewis acid, see: a) cis/trans=4:1; Dhudshia, B.; Cooper, B. F. T.; MacDonald, C. L. B.; Thadani, A. N. Chem. Commun. 2009, 463-465. b) cis/trans=2.2:1; Klitzke, C. F.; Pilli, R. A. Tetrahedron Lett. 2001, 42, 5605-5608. c) cis/trans=2:1; Russowsky, D.; Petersen, R. Z.; Godosi, M. N.; Pilli, R. A. Tetrahedron Lett. 2000, 41, 9939-9942. d) cis/trans=6:1; Hart, D. J.; Sun, L.-Q.; Kozikowski, A. P. Tetrahedron Lett. 1995, 36, 7787-7790. e) cis/trans=3.3:1; Thanning, M.; Wiestrand, L.-G. J. Org. Chem. 1990, 55, 1406-1408.

${ }^{8}$ Kelly, T. R.; Li, Q.; Bhushan, V. Tetrahedron Lett. 1990, 31, 161-164.

${ }^{9}$ Huang, C.; Huang, Y.; Akhmedov, N. G.; Popp, B. V.; Petersen, J. L.; Wang, K. K. Org. Lett. 2014, 16, 2672-2675. 
10 a) Söderberg, B. C. G.; Hubbard, J. W.; Rector, S. R.; O’Neil, S. N. Tetrahedron 2005, 61, 3637-3649. b) Söderberg, B. C. G.; Rector, S. R.; O’Neil, S. N. Tetrahedron Lett. 1999, 40, 3657-3660.

${ }^{11}$ For applications of this type of cyclization in total synthesis, see: a) Cummings, M. M.; Clawson, R. W.; Sharma, S. B.; Byerly, R. A.; Akhmedov, N. G.; Söderberg, B. C. G. Tetrahedron 2011, 67, 4753-4757. b) Clawson, R. W.; Dacko, C. A.; Deavers, R. E.; Akhmedov, N. G.;

Söderberg, B. C. G. Tetrahedron 2009, 65, 8786-8793. c) Clawson, R. W.; Söderberg, B. C. G. Tetrahedron Lett. 2007, 48, 6019-6021. d) Kuethe, J. T.; Wong, A.; Davies, I. W. Org. Lett. 2003, 5, 3721-3723. e) Scott, T. L.; Söderberg, B. C. G. Tetrahedron 2003, 59, 6323-6332. f) Dantale, S. W.; Söderberg, B. C. G. Tetrahedron 2003, 59, 5507-5514. g) Söderberg, B. C.; Chisnell, A. C.; O’Neil, S. N.; Shriver, J. A. J. Org. Chem. 1999, 64, 9731-9734. 


\section{Graphical Abstract for:}

Total synthesis of the tetracyclic indole alkaloid ht-13-A.

Yilin Zhang, Ian W. McArdle, Jeremiah W. Hubbard, Novruz G. Akhmedov, and Björn

C. G. Söderberg.*

C. Eugene Bennett Department of Chemistry, West Virginia University, Morgantown, West Virginia 26506-6045, USA.

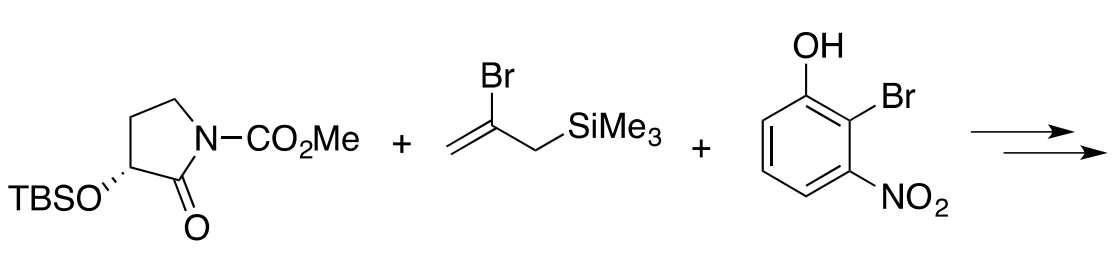<smiles>CN1CCC2Oc3cccc4[nH]cc(c34)CC21</smiles> 